\title{
IMMUNOLOGICAL RELATIONSHIPS AMONG THE STRAINS OF CHLAMYDOMONAS
}

\author{
CHUBUN T. SATO AND KEN-ICHI TOMOCHIKA
}

Department of Biology, Faculty of Science, Okayama University, Okayama 700

Received July 9, 1969

Various immunological analyses have made a valuable contribution in definite detection of the differences in antigenic specificities of the proteins. Using a serological technique, Huter and Provasoli (1951) detected inter-species differences among the 3 species of Chlamydomonas, namely C. moewusii, C. reinhardtii and C. chlamydogama. Minitz and Lewine (1951) tried to differentiate mating types of $C$. moewusii. No distinction could be found between them by a complement fixation method. Gowans (1963) reported that $C$. eugametos and $C$. moewusii were very closely related immunologically, concluding that they are probably conspecific. By means of immunological techniques, such as double diffusion, absorption and immunoelectrophoresis, Brown and Walne (1967) analyzed the antigens of Chlamydomonas. They found serological evidence of phylogenic relationships among the 3 species, $C$. moewusii, $C$. eugametos and $C$. reinhardtii, and reported that there was a distinguishable antigenic difference between mutants and wild types from which the mutants were derived.

In order to make clear the antigenic variability among some strains of Chlamydomonas reinhardtii as the base for a further study, the authors have attempted an immunoelectrophoretic comparison of the antigenic proteins extracted from the cell.

\section{MATERIALS AND METHODS}

Twelve strains of Chlamydomonas reinhardtii were kindly supplied by Prof. Y. Tsubo, Kobe University. The strains used in this experiment were $21 \mathrm{gr}$ (wild type), 2502C, 6301A, 6301B, 6301C, 6301D, 5065B, 5065C, 6222A, 6222B, 6222C and 6222D (Table 1, Tsubo). The culture conditions were the same as those previously described by Sagar (1955). The cells from fresh subculture were sonically disrupted by a treatment at $20 \mathrm{KC}$ for $5 \mathrm{~min}$. After extraction in a $0.9 \%$ saline solution, a clear extract was obtained by centrifugation at 40,000 r. p. m. for $30 \mathrm{~min}$. Approximate protein concentrations were determined by the Biulet method. An antigen for immunization was prepared from the diluted extract with the saline solution. This extract contained 2.8-5.0 $\mathrm{mg}$ protein per $1 \mathrm{ml}$. Rabbits were immunized with the antigens into the footpads and the inter-muscles. Immunization was completed by 5 to 10 injections given over 5 months. Thus, an antiserum to the extracts of 21 gr was produced. The immunoelectrophoretic technique used in the present study was a modification of the one developed by Williams and Grabar (1955). The immunoelectrophoretic patterns on the 
Table 1. Index of Strains

\begin{tabular}{|c|c|c|c|c|c|}
\hline \multirow{2}{*}{$\frac{\text { Strain }}{21 \mathrm{gr} \text { (wild type) }}$} & \multicolumn{5}{|c|}{ Characters } \\
\hline & $\mathrm{mt}^{+}$ & $\mathrm{Y}_{1}+$ & ss & $\mathrm{mss}$ & as \\
\hline $2502 \mathrm{C}$ & $\mathrm{mt}^{-}$ & $\mathrm{Y}_{1}^{-}$ & ss & $\mathrm{mss}$ & as \\
\hline $6301 \mathrm{~A}$ & $\mathrm{mt}^{-}$ & $\mathrm{Y}_{1-}^{-}$ & ss & $\mathrm{msr}$ & as \\
\hline $6301 \mathrm{~B}$ & $\mathrm{mt}^{-}$ & $Y_{1}+$ & ss & $\mathrm{msr}$ & ar \\
\hline $6301 \mathrm{C}$ & $\mathrm{mt}+$ & $\mathrm{Y}_{1}+$ & $\mathrm{sr}_{1}$ & $\mathrm{mss}$ & as \\
\hline $6301 \mathrm{D}$ & $\mathrm{mt}^{+}$ & $\mathrm{Y}_{1}-$ & $\mathrm{sr}_{1}$ & mss & ar \\
\hline $5065 \mathrm{~B}$ & $\mathrm{mt}+$ & $\mathrm{Y}_{1}^{+}$ & $\mathrm{sr}_{2}$ & $\mathrm{msr}$ & ar \\
\hline $5065 C$ & $\mathrm{mt}^{-}$ & $\mathrm{Y}_{1-}^{-}$ & $\mathrm{sr}_{2}$ & $\mathrm{msr}$ & ar \\
\hline $6222 \mathrm{~A}$ & $\mathrm{mt}^{+}$ & $\mathrm{Y}_{1}^{+}$ & $\mathrm{sr}_{2}$ & mss & as \\
\hline $6222 \mathrm{~B}$ & $\mathrm{mt}^{+}$ & $\mathrm{Y}_{1}^{-}$ & $\mathrm{sr}_{2}$ & $\mathrm{msr}$ & ar \\
\hline $6222 \mathrm{C}$ & $\mathrm{mt}^{-}$ & $\mathrm{Y}_{1}^{-}$ & $\mathrm{sr}_{2}$ & mss & ar \\
\hline $6222 \mathrm{D}$ & $\mathrm{mt}^{-}$ & $\mathrm{Y}_{1}+$ & $\mathrm{sr}_{2}$ & $\mathrm{msr}$ & as \\
\hline
\end{tabular}

$\mathrm{mt}^{+}$: mating type plus, $\mathrm{mt}^{-}$: mating type minus, $\mathrm{Y}_{1^{+}}$: green in dark, $\mathrm{Y}_{1^{-}}$: yellow in dark, ss: streptomycin sensitive, $\mathrm{sr}_{1}$ : streptomycin resistance, $\mathrm{sr}_{2}$ : streptomycin resistance, nonchromosomal, mss: methyonin sulfoxin sensitive, msr: methyonin sulfoxin resistance, as: actidion sensitive, ar: actidion resistance.

6th day were adopted as the criterion of the present comparison.

\section{RESULTS}

At least 14 precipitin lines could be counted by the immunoelectrophoretic analysis of the extract of $21 \mathrm{gr}$ against the anti $21 \mathrm{gr}$ serum (Fig. 1). In detail, 2 of the 14 precipitin lines were formed in $\alpha_{1}$-region and the other $3,2,4$ and 3 lines were obtained in $\alpha_{2^{-}}, \alpha_{3^{-}}, \beta$ - and $\gamma$-regions respectively. Extracts from 12 strains of $C$. reinhardtii were made to react with the anti 21 gr serum by immunoelectrophoresis. When the patterns obtained with mutants and with wild strains were compared, those of the $21 \mathrm{gr}$ and $2502 \mathrm{C}$ were identical, having 14 lines, but there were some differences in pattern among the $21 \mathrm{gr}$ group above mentioned and the groups of the remaining strains
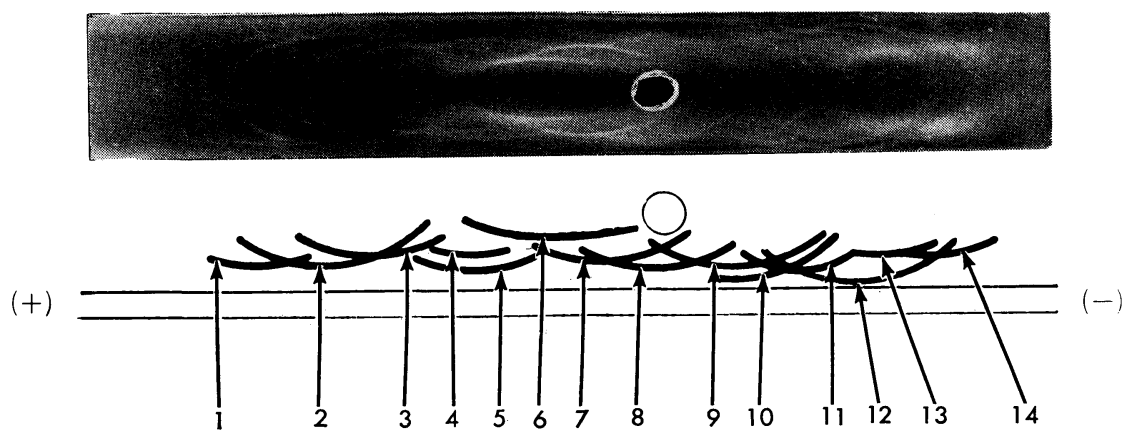

Fig. 1. The immunoelectrophoretic pattern of the wild (21 gr) strain and its schematic drawing. 


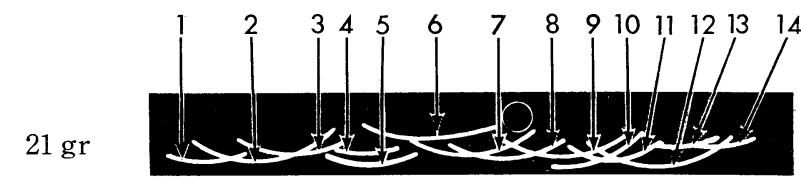

$2502 \mathrm{C}$

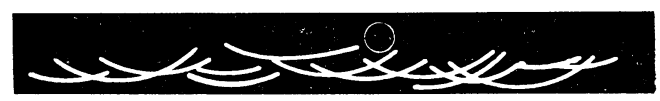

$6301 \mathrm{~A}$

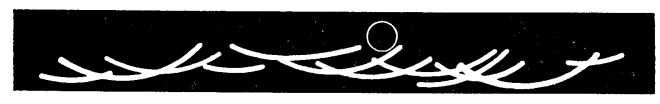

$6301 \mathrm{~B}$

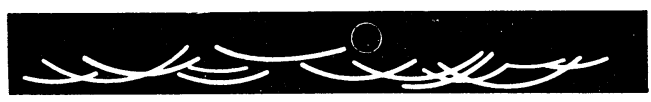

$6301 \mathrm{C}$

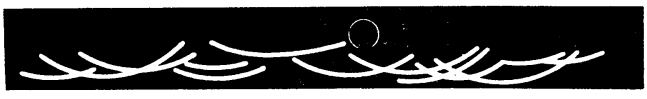

$6301 \mathrm{D}$

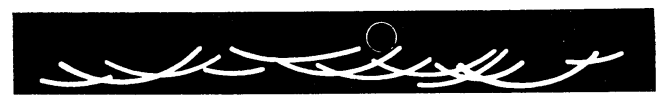

5065 B

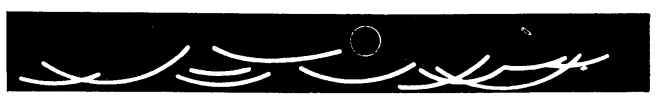

$5065 \mathrm{C}$

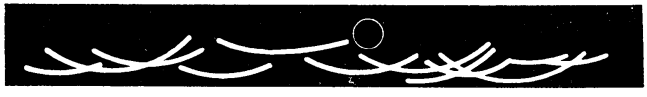

$6222 \mathrm{~A}$

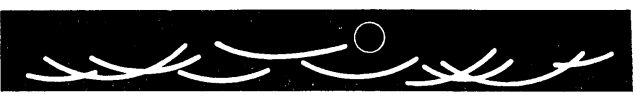

$6222 \mathrm{~B}$

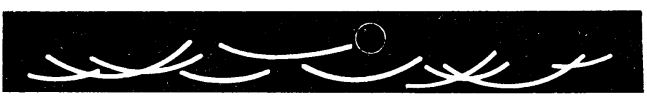

$6222 \mathrm{C}$

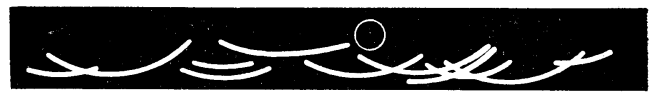

$6222 \mathrm{D}$

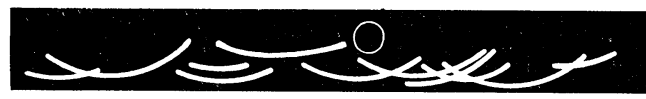

Fig. 2. Comparison of patterns between the wild strain and the 11 mutant strains. 
(Fig. 2). The modification in pattern was found in the number and the intensity of the precipitin lines. The number of antigens in the 12 strains tested are shown in Fig. 3. Strains $6301 \mathrm{~B}$ and $6301 \mathrm{C}$ showed the pattern with 13 lines, that is, one of the 14 lines in the reaction of the $21 \mathrm{gr}$ did not appear. In the patterns of $6301 \mathrm{~A}, 6301 \mathrm{D}$ and $5065 \mathrm{C}, 2$ of the 14 lines were lacking, and the lack of 3 lines was recognized in the patterns of $6222 \mathrm{C}, 6222 \mathrm{D}$ and $5065 \mathrm{~B}$. Strains $6222 \mathrm{~A}$ and $6222 \mathrm{~B}$ belonged to the group which lacked 4 lines. In the patterns of all the strains examined, whether wild or mutant, the lst and the 2nd lines in $\alpha_{1}$-region, the 6 th in $\alpha_{3}$-region, the 8 th, 10 th and the 11th lines in $\beta$-region, and the 12 th and the 14 th in $\gamma$-region were common to all the strains tested, while the $3 \mathrm{rd}, 4 \mathrm{th}, 5 \mathrm{th}, 7 \mathrm{th}, 9 \mathrm{th}$ and 13 th lines were specific of certain strains. These 6 lines, the 5th, 7th and 12 th in 6301 and the 3rd, 4th and 9th in 6222 , segregated in the ratio $2: 2$ for the formation of the immune-line.

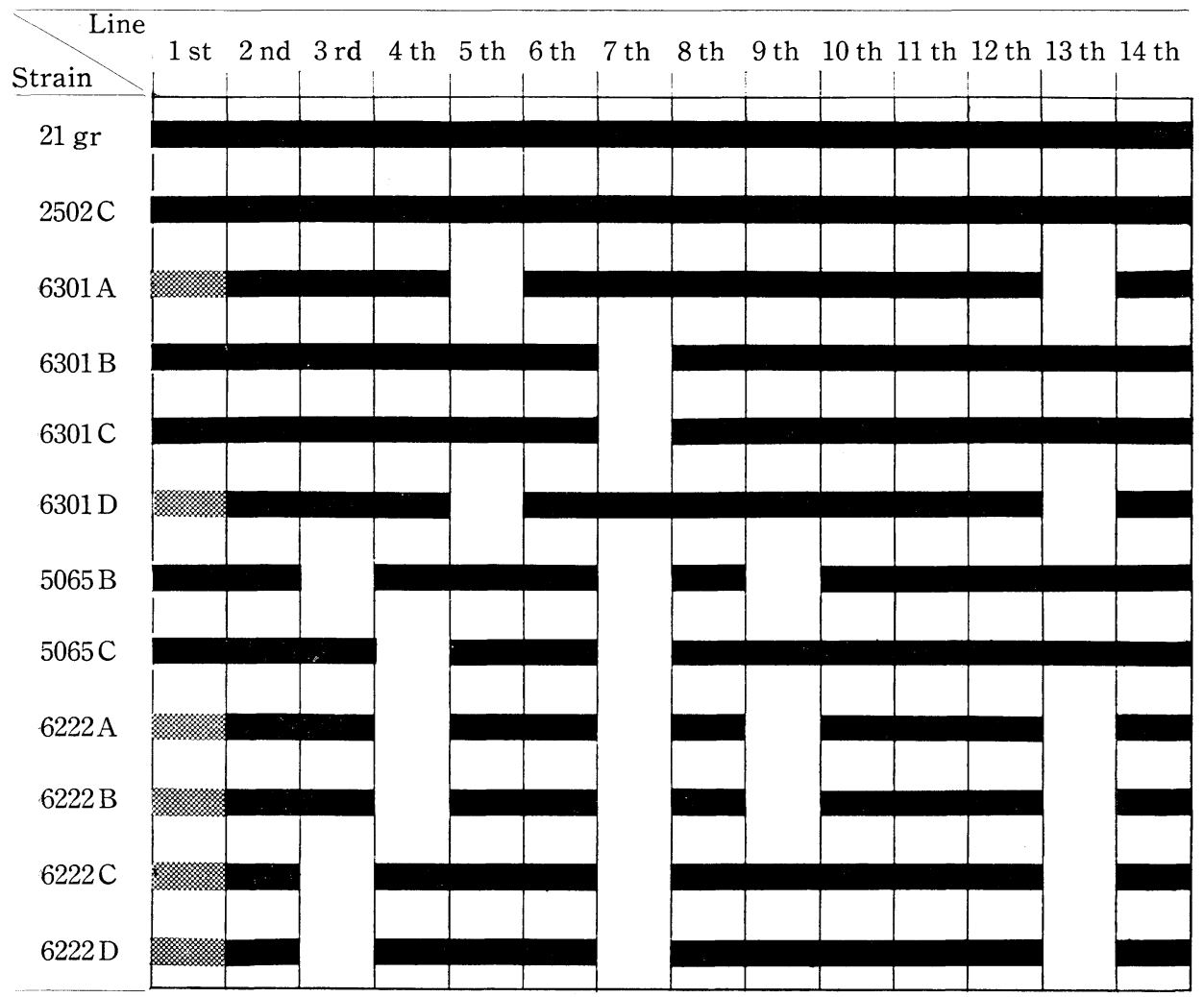

Fig. 3. Numbers of antigens separated by immunoelectrophoresis.

\section{DISCUSSION}

The common antigenicity of a cell extract as a mixture of antigens in the strains examined may signify that most of the metabolic and biosynthetic pathways are similar or common to all the strains tested. Our results also indicate that wild $C$. reinhardtii 
can be distinguished from its several mutants, these being distinguished from one another by immunoelectrophoresis. In the immunoelectrophoretic analysis of the cytoplasmic proteins from Neurospora crassa, Williams and Tatum (1966) fractionated more than 30 antigenic components, and suggested some prominent phyletic affinities among antigens within the class Ascomycetes. On the basis of antigenic specificities, immunological grouping is possible. The close relationship between $21 \mathrm{gr}$ and $2502 \mathrm{C}$ is well recognized, and among the remaining strains, the 6301 group (6301A-6301D) is more closely related to the 21 gr than the 6222 group (6222A-6222D) is. While the 21 gr pattern showed 14 lines, the 6222 group lacked 3 or 4 lines and the lack of 1 or 2 lines was observed in the 6301 group.

The data obtained in this experiment suggest that the similarity in antigenic specificities may reflect genealogical affinities in the cytoplasmic contents. On the basis of such techniques as double diffusion, absorption and immunoelectrophoresis, Brown and Walne (1967) revealed antigenic differences among some species of Chlamydomonas, between $C$. moewusii and 2 of its varieties, and between wild types and certain mutants. They also reported that mating type specificities were recognizable immunologically but very subtle. Meanwhile, using serological methods, Huter and Provasol (1951) reported that serological differences among Chlamydomonas moewusii, $C$. reinhardtii and $C$. chlamydogama were detectable, but mating types were unable to differentiate. Using a complement fixation technique, Minitz and Lewine (1951) could not find serological differences between the mating types of $C$. moewusii. These results are supported by the data of Gowans (1963), in which no consistent serological differences were found between the mating types of $C$. eugametos.

The same strains as were used in the present experiment have been well studied with respect to such genetic characters as the mating type, streptomycin resistance, methyonin sulfoxinin resistance, actidion resistance and $\mathrm{Y}_{1}{ }^{+}$or $\mathrm{Y}_{1}{ }^{-}$(Smith and Regnery 1950; Sagar 1954; Sagar 1955; Sagar and Tsubo 1961; Sagar and Tsubo 1962; Sagar and Ramanis 1965). It was examined whether the immunoelectrophoretic pattern would correspond to the genetically marked strain. But there was no indication that the antigenic specificities shown in our immunoelectrophoretic data might be associated with any of the identified mutant characters including the mating type. However, the fact that the 5th, 7th and 13th lines in 6301 and the 3rd, 4th and 9th lines in 6222 segregated in the ratio $2: 2$ suggests that these characters may behave as a single Mendelian character. It is because each of $6301 \mathrm{~A}, \mathrm{~B}, \mathrm{C}$ and $\mathrm{D}$ is a progeny colony of tetrads obtained from a zygote. This is also the case in 6222 . The possibility of any relationship between lack of specificities and deficiency of other identified genetic characters remains to be examined.

\section{SUMMARY}

Immunoelectrophoretic analysis of the whole cell extract of Chlamydomonas reinhardtii by using the antiserum against the wild strain (21gr) demonstrated at least 14 antigenic components. When 11 mutants were compared with the wild strain, a certain 
difference in pattern was found in the number and the intensity of the precipitin lines. Of the 14 immune-precipitin lines in the wild strain, 8 were common to all the strains tested, and the remaining 6 were variable according to the strain. The present data suggest the division of $C$. reinhardtii into some immunologically related groups.

The correspondence of the immunoelectrophoretic pattern to the genetically marked strain was examined. However, there was no indication of the association of antigenic specificities with any identified mutant characters. Any immunological differences in the mating type could not be found, either. However, the 2:2 segregation for the formation of some of the immune-lines suggests that these may be a single Mendelian character.

\section{ACKNOWLEDGMENTS}

The authors are very grateful to Professor E. Okura, Department of Biology, Faculty of Science, Okayama University, for checking the manuscript with valuable advice. Thanks are also due to Professor Y. Tsubo of Kobe University for his helpful suggestions and supply of Chlamydomonas reinhardtii.

\section{LITERATURE CITED}

Brown, R. L., and P. L. Walne, 1967 Comparative immunology of selected wild types, varieties and mutants of Chlamydomonas. J. Protozool. 14: 365-373.

Gowans, C. S., 1963 The conspecificity of Chlamydomonas eugametos and C. moewusii: An experimental approach. Phycologia 3: 37-44.

Huter, S. H., and L. Provasoli, 1951 The phytoflagellates. In "The Biochemistry and Physiology of Protozoa" (A. Lwoff, ed.) pp. 27-128. Academic Press, New York.

Minitz, R. H., and R. A. Lewine, 1951 Studies on the flagella of algae. V. Serology of paralyzed mutants of Chlamydomonas. Can. J. Microbiol. 1: 65-67.

Sagar, R., 1954 Mendelian and non-Mendelian inheritance of streptomycin resistance in Chlamydomonas reinhardtii. Proc. Natl. Acad. Sci. U.S. A. 40: 356-363.

Sagar, R., 1955 Inheritance in the green alga Chlamydomonas reinhardtii. Genetics 40: 476-489.

Sagar, R., and Y. Tsubo, 1961 Genetic analysis of streptomycin resistance and dependence in Chlamydomonas. Z. Vererb-lehre 92: 430-438.

Sagar, R., and Y. Tsubo, 1962 Mutagenic effects of streptomycin in Chlamydomonas. Arck. Microbiol. 42: 159-175.

Sagar, R., and Z. Ramainis, 1965 Recombination of nonchromosomal genes in Chlamydomonas. Proc. Natl. Acad. Sci. U. S. A. 53: 1053-1061.

Smith, G. M., and D. C. Regnery, 1950 Inheritance of sexuality in Chlamydomonas reinhardtii. Proc. Natl. Acad. Sci. U. S. A. 36: 246-248.

Tsubo, Y., Personal communication.

Williams, C. A., and P. Grabar, 1955 Immuno-electrophoretic studies on serum proteins. J. Immunol. 74: $158-168$.

Williams, C. A., and E. L. Tatum, 1966 Immunoelectrophoretic analysis of cytoplasmic proteins of Neurospora crassa. J. Gen. Microbiol. 44: 59-68. 